\title{
Utilization of HIV Test Service Among Pregnant Women's Partners and Its Associated Factors in Selected Sub-Cities of Addis Ababa, 2019: A Community-Based Cross-Sectional Study
}

This article was published in the following Dove Press journal:

HIVIAIDS - Research and Palliative Care

\author{
Mesfin Markos Kachero (D) \\ Aseb Arba Kinfe (D) ${ }^{2}$ \\ 'School of Midwifery, College of \\ Medicine and Health Sciences Wolaita \\ Sodo University, Wolaita Sodo, Southern \\ Ethiopia; ${ }^{2}$ School of Nursing, College of \\ Medicine and Health Sciences Wolaita \\ Sodo University, Wolaita Sodo, Southern \\ Ethiopia
}

Background: Significant progress has been made towards achieving the 90-90-90 global targets by 2020 . Nationally, 72\% of HIV-positive people aged 15-64 years in urban areas were aware of their HIV status. There is low habit of male partner accompanying pregnant women during ANC visit. This study assessed the HIV test service utilization and associated factors among pregnant women's partners in Addis Ababa.

Methods: A community-based cross-sectional study design was conducted from January to February 2020 in Addis Ababa town. A multistage sampling method was used to recruit 812 participants. Data were entered into EpiData version 4.1 and analysis was done by using SPSS version 25.0. The presence and strength of significant association with outcome variables in multivariable analysis were determined with $\mathrm{P}<0.05$ and at $95 \% \mathrm{CI}$, respectively. Results: Among respondents, 63.7\% [95\% CI (60-67\%)] of pregnant woman partners had tested for HIV/AIDS. Knowledge on the route of HIV transmission from mother to child $(\mathrm{AOR}=1.9,95 \% \mathrm{CI}(1.3-2.7))$, knowledge on ways of prevention of HIV from mother to child transmission (AOR $=0.26,95 \%$ CI $(0.17-0.38)$ ), previous history of couple HIV counseling $(\mathrm{AOR}=3.7,95 \% \mathrm{CI}(2.3-6.1))$, discussion about HCT and ANC services with a partner $(\mathrm{AOR}=6.3,95 \% \mathrm{CI}(4.0-9.8)$ ), heard about discordant HIV test result (AOR=1.6, 95\% CI (1.4-4)) were significantly associated with partner HIV test.

Conclusion: HIV testing service utilization among male partners of pregnant women was good in the study area. The knowledge on ways of prevention of HIV from mother to child transmission, those who received couple HIV counseling before, those who discussed HCT at ANC services with a partner, and heard about discordant HIV test results were predictors of HIV test utilization among pregnant women partner. Therefore, increasing community awareness on the pregnant women partner testing should be planned to enhance male partner HIV testing during in antenatal care follow-up.

Keywords: HIV, partner HIV test, pregnant woman

\section{Introduction}

Human immune deficiency (HIV) is a sexually transmitted infection (STI) that can also be spread by contact with infected blood or from mother to child during pregnancy, childbirth, or breast-feeding. ${ }^{1}$ If HIV is left untreated, a person's immune system will get weaker and weaker until it can no longer fight off lifethreatening infections and diseases. ${ }^{2}$ The HIV testing programs are implemented to
Correspondence: Aseb Arba Kinfe Email 40aseb@gmail.com 
reach people living with HIV who are unaware of their status, or those at a higher risk of acquiring HIV, and are critical to an effective HIV response. HIV testing goals call for $90 \%$ of all people living with HIV to know their status by 2020 , as described in the UNAIDS' $90-90-90$ Fast-Track Targets. ${ }^{3}$

The World Health Organization recommends offering HIV testing and counseling to couples, wherever HIV testing and counseling are available, including in antenatal clinics to prevent PMTCT. The success in integrating HIV testing into antenatal and other sexual and reproductive health services has seen an increasing number of women testing. ${ }^{4}$ One of the ways a male partner get a chance of testing is through the provision of prevention of mother to child transmission (PMTCT) services at antenatal clinics. Couple HIV testing and counseling (CHTC) offers couples the opportunity to test, receive their results, and mutually disclose their status in an environment where support is provided by a counselor/health worker. A range of prevention, treatment, and support options can then be discussed and decided upon together, depending on the status of each partner. $^{5}$

Low uptake of HIV testing services in sub-Saharan Africa (SSA) is among the key barriers to meet the 9090-90 targets established by UNAIDS and to improve the effectiveness of HIV treatment as prevention. HIV testing among men particularly remains low in many countries, as does the knowledge of HIV status among HIV-infected persons. ${ }^{6,9,12,19}$ The national prevalence of HIV infection among those aged 15-49 years went down to 0.9 though there is heterogeneity by sex, geography and population groups - remaining high among women and urban areas in Ethiopia. Similarly, though not uniform significant progress has been made towards achieving the 90-90-90 global targets by 2020 which is evidenced by a recent population-based HIV impact assessment survey where $72 \%$ of HIV-positive people aged 15-64 years in urban areas were aware of their HIV status, $99 \%$ of those aware of their HIV-positive status reported current use of ART, and $90 \%$ of those reporting current use of ART were virally suppressed. ${ }^{26}$

\section{Significance of the Study}

HIV/AIDS is still a priority Public Health problem. Knowing HIV status is essential for prevention, treatment and to get support. Many women, who are living with HIV, are unable to disclose their status due to different reasons. To breakdown, this problem partner HIV counseling and testing are very essential. Partner HIV testing can also increase the retention in PMTCT services and treatment adherence.

However, numerous reasons for non-participation of male partners in HIV counseling and testing have been gained from studies that primarily focused on women as respondents. Therefore, this study was conducted to assess the level of partner HIV test utilization and associated factors. The study finding will be important to guide public health planners and implementers in planning and designing appropriate intervention strategies to increase partner testing.

\section{Objectives}

- To assess the level of utilization of HIV test service among Pregnant Women's Partners in Selected SubCities of Addis Ababa, 2020.

- To identify the factors associated with the utilization of HIV test service among male partner of pregnant women in Selected Sub-Cities of Addis Ababa, 2020.

\section{Materials and Methods \\ Study Design}

A community-based cross-sectional study design was conducted to assess the level of male partner's HIV test service utilization and its associated factors in selected sub-cities of Addis Ababa.

\section{Study Area and Period}

The study was conducted in selected sub-cities of Addis Ababa city administration; the capital city of Ethiopia from January 1 to February 30, 2020. The city has 10 subcities and 116 Woredas. There are 5 hospitals owned by the Addis Ababa health bureau, 4 by the Federal Ministry of Health, 1 by Addis Ababa University, 3 by nongovernmental Organizations, 3 by the defense force and police, and 34 by private owners. There are 100 public health centers and around 700 private clinics out of which 75 are higher clinics. ${ }^{24}$

\section{Population}

All male partners of pregnant women in Addis Ababa City were the Source population for the current study. All male partners of pregnant women who were living in selected sub-cities were the Study population.

\section{Inclusion and Exclusion Criteria}

All male partners of pregnant women who lived more than 6 months in selected sub-cities of Addis Ababa were 
included in the study. All male partners of pregnant women who are unable to speak and hear were excluded.

\section{Sample Size and Sampling Procedure}

The sample size was calculated for both objectives and the maximum sample size was obtained using the first objective. The following assumptions were used for sample size calculations: a proportion of $40.1 \%$ of male partner testing in Gondar town, ${ }^{16}$ level of significance 5\% $(\alpha=0.05), 95 \%$ confidence level $(Z \alpha / 2=1.96)$ and absolute precision or margin of error $5 \%(\mathrm{~d}=0.05)$, power $80 \%$, ratio of exposed to unexposed 1:1, and design effect of 2 .

The calculated maximum initial sample size was 369 . Therefore, by adding $10 \%$ for possible non-response rate, the sample size required for the study was 812 .

\section{Sampling Procedures}

A multistage sampling method was used to select study participants. From the total 10 sub-cities, three sub-cities were selected by the lottery method. Then, five woredas from each selected sub-cities were selected randomly. The numbers of participants from each Woreda were determined by proportionate allocation of sample size to number of pregnant women in the Woreda by reviewing the annual expected number of pregnant woman report of 2012 E.C/2019. Systematic random sampling was applied to select households with a pregnant mother and to interview her male partner.

\section{Study Variables}

Dependent Variable

Male partner HIV test utilization.

\section{Independent Variables}

\section{Socio-Demographic Variables}

Age, occupation, marital status, time period of living together, educational status, average-monthly income, spouse education.

\section{Knowledge Related Variables}

Awareness on the availability of HIV test services in ANC, knowledge about HIV transmission, knowledge about the route of MTCT of HIV transmission, knowledge about PMTCT and heard about discordant HIV test result.

\section{Family Communication}

Communication between partners about ANC and HCT.
History of HIV Test

Previous couple HIV counseling and testing in current pregnancy.

\section{Operational Definitions}

Partner HIV Test Utilization

When husbands or partners of pregnant woman have tested for HIV on ANC. ${ }^{10}$

\section{Knowledge on the Route of HIV Transmission}

When respondents know at least two routes of HIV from three routes of transmission. ${ }^{10}$

Knowledge on the Route of HIV Transmission from Mother to Child

When respondents know at least two routes of HIV transmission from mother to child from three routes of transmission.

\section{Knowledge About PMTCT}

When respondents know at least two ways of PMTCT from three ways of PMTCT.

\section{Data Collection Tool and Procedure}

A structured questionnaire was adapted from the result of different researches done on the partner HIV test. It was prepared in English and translated into Amharic and back to English to keep the consistency of the data. The questionnaire had different sections, socio-demographic information, knowledge about HIV transmission, family communication, and experience of counseling and testing for HIV.

The households home from each selected Woreda were identified from the health extension worker's report. Data were collected by going home to home. Each individual was asked for consent before he was interviewed using the questionnaire. All partners of pregnant women in the study areas were eligible to be included in this study.

\section{Data Quality Assurance}

A brief training was given for data collectors on the objective, relevance, and benefits of the study, confidentiality of information, respondent's right, informed consent, and technique of interview supported with a demonstration on how to conduct the interview and overall data collection process before the actual time of data collection. A pre-test was conducted 5\% (41) of the sample size in Yeka sub-city Woreda 06 and some minor modifications 
were done accordingly. The collected data were reviewed and checked for completeness and consistency by the principal investigator and supervisor on daily basis at the spot during the data collection time.

\section{Data Processing and Analysis}

Data were coded and entered into EpiData version 4.6 and analyzed using SPSS software version 25. Descriptive analysis was performed to describe the number and percentage of socio-demographic characteristics of the sample and other variables and presented in tables and graphs. Binary logistic regression was conducted. Bivariate analysis was used to analyze the relationship between the dependent and independent variables. All variables with $\mathrm{P}<0.2$ in bivariate analysis were entered into multivariate analysis to identify factors independently associated with partner HIV test. The significance of odds ratios (OR) was determined with $95 \% \mathrm{CI}$ and $\mathrm{P}<0.05$.

\section{Ethical Consideration}

The ethical approval and clearance was obtained from St. Lideta Medical and Business College. Then, permission and letter of cooperation for the health facilities were obtained from the Addis Ababa Health Bureau. We explained the participants about the purpose of the study, benefits of the study, their right to refuse anytime, and the confidentiality in the language that the participant can understand to comply with the Declaration of Helsinki. An informed voluntary written consent was obtained from each participant before conducting the interview. Any personal identification of the study participants was not recorded during data collection.

\section{Results}

\section{Socio-Demographic Characteristics of the Respondents}

A total of 798 respondents were interviewed with a response rate of $98.2 \%$. The mean age of the study subjects was 37.46 years with a standard deviation of \pm 7.1 years. Among the respondents 397 (49.7\%) were 31-40 years of age, most of the respondents $751(94.1 \%)$ were married. Half of the respondents 405 (50.8\%) who were married stayed together for $1-5$ years and those who lived together 5-10years were $195(24.4 \%)$. The respondents who were interviewed had a college and above 335 (42\%) educational status and 280 (35.1\%) of them completed secondary schools. More than half of respondents were working in private $409(51.3 \%)$ and governmental employment accounts for 247 (31\%). The respondent average monthly income in Ethiopian birr obtained were (1100-4999) which was $380(47.6 \%)$. The respondent's wife age from 21 to 30 years were 376 (47.1\%). The educational status for a respondent's wife who was college and above 294 (36.8\%) and 216 (27.1\%) mothers had secondary school education shown in Table 1.

\section{Knowledge and Awareness About HIV and PMTCT}

The proportion of male respondents who know about HIV transmission by sexual intercourse, sharing sharp material, and mother to the child were $93.4 \%, 87.1 \%$, and $74.4 \%$, respectively. The composite knowledge proportion of HIV transmission was $85.5 \%$. Regarding MTCT, during pregnancy $(76.8 \%)$, during labor and delivery $(68.2 \%)$, during breastfeeding (66.7\%). Of the participants, $63.9 \%$ of them knew about HIV transmission from mother to child. Among the respondents, those who know the method of PMTCT which were antiretroviral therapy during pregnancy was $568(71.2 \%)$, and who knew that provision of ARTs for the newborn could help to reduce MTCT of HIV was $348(43.6 \%)$. The composite knowledge proportion for PMTCT was $38.3 \%$ shown in Table 2.

The respondents who knew that there is HIV counseling and testing (HCT) during ANC visits were 85.0\%. Those who believed that partner HIV counseling and testing is necessary were 763 (95.6\%). A three fourth of the participants 599 (75.1\%) had heard HIV test discordant result.

\section{HIV Tested the Status of Partners of Pregnant Women}

In this study, the proportion of partners of pregnant women who had tested was $63.7 \%$ (95\% CI $0.60-0.67)$ who had tested for HIV/ADIS came with their wives to ANC and received HIV counseling and testing together. Slightly more than one-fourth $27.2 \%$ ) of the participants decided by own and $18.3 \%$ partner invitation from health-care provider to test for HIV shown in Figure 1

Participants who had received a couple of counseling and testing before were 593 (74.3\%). The respondents who ever discussed ANC and HIV tests were 482 (60.4\%). Partners who had not tested for HIV/ADIS gave a reason for being busy $16.3 \%$ and proxy testing $10.3 \%$ as stated in Figure 2. 
Table I Socio-Demographic Characteristics of Partner of Pregnant Woman in Addis Ababa, Ethiopia, 2019

\begin{tabular}{|c|c|c|c|}
\hline Variables & Category & $\begin{array}{l}\text { Frequency } \\
\text { (n) }\end{array}$ & Percent \\
\hline Age (years) & $\begin{array}{l}<20 \\
2 I-30 \\
3 I-40 \\
4 I-50 \\
>5 I\end{array}$ & $\begin{array}{l}2 \\
143 \\
397 \\
227 \\
29\end{array}$ & $\begin{array}{l}0.3 \\
17.9 \\
49.7 \\
28.4 \\
3.6\end{array}$ \\
\hline Marital status & $\begin{array}{l}\text { Married } \\
\text { Unmarried } \\
\text { Divorced }\end{array}$ & $\begin{array}{l}751 \\
42 \\
5\end{array}$ & $\begin{array}{l}94.1 \\
5.3 \\
0.6\end{array}$ \\
\hline $\begin{array}{l}\text { Duration } \\
\text { of marriage (years) }\end{array}$ & $\begin{array}{l}<1 \\
1-5 \\
5-10 \\
>10\end{array}$ & $\begin{array}{l}99 \\
405 \\
195 \\
52\end{array}$ & $\begin{array}{l}12.4 \\
\\
50.8 \\
24.4 \\
6.5\end{array}$ \\
\hline Educational status & $\begin{array}{l}\text { No formal } \\
\text { education } \\
\text { Primary school } \\
(1-8) \\
\text { Secondary } \\
\text { school(9-12) } \\
\text { College and } \\
\text { above }\end{array}$ & $\begin{array}{l}44 \\
139 \\
280 \\
335\end{array}$ & $\begin{array}{l}5.5 \\
17.4 \\
35.1 \\
42.0\end{array}$ \\
\hline Occupation & $\begin{array}{l}\text { Governmental } \\
\text { employee } \\
\text { Private } \\
\text { NGO } \\
\text { Daily labor }\end{array}$ & $\begin{array}{l}247 \\
409 \\
83 \\
59\end{array}$ & $\begin{array}{l}31.0 \\
51.3 \\
10.4 \\
7.4\end{array}$ \\
\hline $\begin{array}{l}\text { Respondent } \\
\text { personal average } \\
\text { monthly income } \\
\text { (Eth.Birr) }\end{array}$ & $\begin{array}{l}<1000 \\
1100-4999 \\
5000-9999 \\
>10,000\end{array}$ & $\begin{array}{l}380 \\
347 \\
58\end{array}$ & $\begin{array}{l}1.6 \\
\\
\\
47.6 \\
43.5 \\
7.3\end{array}$ \\
\hline $\begin{array}{l}\text { Age of women } \\
\text { (years) }\end{array}$ & $\begin{array}{l}<20 \\
21-30 \\
31-40 \\
>41\end{array}$ & $\begin{array}{l}14 \\
376 \\
368 \\
40\end{array}$ & $\begin{array}{l}1.8 \\
47.1 \\
46.1 \\
5.0\end{array}$ \\
\hline $\begin{array}{l}\text { Educational status } \\
\text { of women }\end{array}$ & $\begin{array}{l}\text { No formal } \\
\text { education } \\
\text { Primary school } \\
(1-8) \\
\text { Secondary } \\
\text { school (9-12) } \\
\text { College and } \\
\text { above }\end{array}$ & $\begin{array}{l}90 \\
198 \\
216 \\
294\end{array}$ & $\begin{array}{l}11.3 \\
24.8 \\
27.1 \\
36.8\end{array}$ \\
\hline
\end{tabular}

\section{Factors Associated with a Partner of} Pregnant Woman HIV Test Status

In bivariate analysis respondents who had a college and above educational status were 7.9 times more likely to be tested than primary attended $(\mathrm{COR}=7.9,95 \% \mathrm{CI}(4.0-$ 15.8). The partner who had been employed in the governmental institution were 7.3 times more likely tested compared to a private organization $(\mathrm{COR}=7.3,95 \% \mathrm{CI}$ (3.9-13.5). Partners who know the presence of HCT during ANC were more likely tested than their counterparts $(\mathrm{COR}=5.3,95 \%$ CI $(3.5-8.1)$.

In multivariate analysis, knowledge on the route of HIV transmission from mother to child, knowledge on ways of prevention of HIV from mother to child transmission, those who received couple HIV testing before, discussed HCT\& ANC services with a partner, heard about discordant HIV test result were significantly associated with partner HIV test.

The respondent who knew the route of HIV transmission from mother to child was 1.9 more likely to test than who had no knowledge (AOR=1.9, 95\% CI (1.3-2.7)). Participants who do not know ways of prevention of HIV transmission from mother to child were $74 \%$ less likely to be tested for HIV/AIDS than those who know ways of PMTCT (AOR $=0.26,95 \%$ CI $(0.17-0.38))$. Those who received couple HIV counseling and testing before were 3.7 times likely to have partner HIV test than those who do not have received couple HIV counseling and testing (AOR $=3.7,95 \%$ CI (2.3-6.1)). Couples who ever discussed ANC and HCT were 6.3 times likely to have HIV test (AOR=6.3, 95\% CI (4.0-9.8)) compared to their counterparts. Respondents who heard about discordant HIV test results were 2.3 times more likely to have HIV tests compared to their counterparts (AOR $=2.3$, 95\% CI (1.4-4.0)) as shown in Table 3.

\section{Discussion}

This study findings show that about $63.7 \%$ (95\% CI 60-67\%) of the men of pregnant woman partners had tested for HIV/ AIDS. This finding is higher than to study conducted in Goba and Gondar town which was $22.7 \%$ and $40.1 \%$, respectively. ${ }^{16,17}$ The possible reasons for this might be the easily accessibility of transportation to reach health facilities. However, this study is lower than finding in a survey conducted by Abraham Haileamlak in Ethiopia (72\%), ${ }^{26}$ a study conducted in Rwanda which was $81 \%$ of the male partners being tested ${ }^{5}$ and also a study conducted in Uganda revealed that the majority (more than 90\%) of male partners who 
Table 2 Knowledge About HIV and PMTCT of Partners of Pregnant Women in Addis Ababa, Ethiopia, 2019

\begin{tabular}{|c|c|c|c|c|}
\hline \multirow[t]{2}{*}{ Variables } & \multicolumn{2}{|l|}{ Yes } & \multicolumn{2}{|l|}{ No } \\
\hline & Frequency & Percent & Frequency & Percent \\
\hline Knowledge on modes of HIV transmission & 682 & 85.5 & 116 & 14.5 \\
\hline Unprotected sexual intercourse & 745 & 93.4 & 53 & 6.6 \\
\hline Sharing of sharp material with infected person & 695 & 87.1 & 103 & 12.9 \\
\hline Mother-to-child & 594 & 74.4 & 204 & 25.6 \\
\hline Knowledge on route of MTCT & 510 & 63.9 & 288 & 36.1 \\
\hline During pregnancy & 613 & 76.8 & 185 & 23.2 \\
\hline During labour and delivery & 544 & 68.2 & 254 & 31.8 \\
\hline During breastfeeding & 532 & 66.7 & 266 & 33.3 \\
\hline Knowledge on PMTCT & 306 & 38.3 & 492 & 61.7 \\
\hline ART during pregnancy & 568 & 71.2 & 230 & 28.8 \\
\hline Delivering by $\mathrm{C} / \mathrm{S}$ & 285 & 35.7 & 513 & 64.3 \\
\hline Giving ART to the newborn & 348 & 43.6 & 450 & 56.4 \\
\hline
\end{tabular}

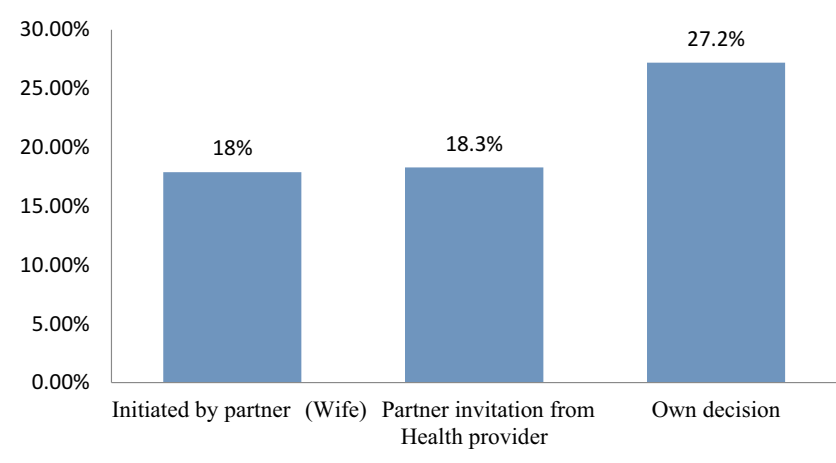

Figure I Partners of pregnant woman decision made to get HIV counseling and testing, in Addis Ababa, Ethiopia, 2019.

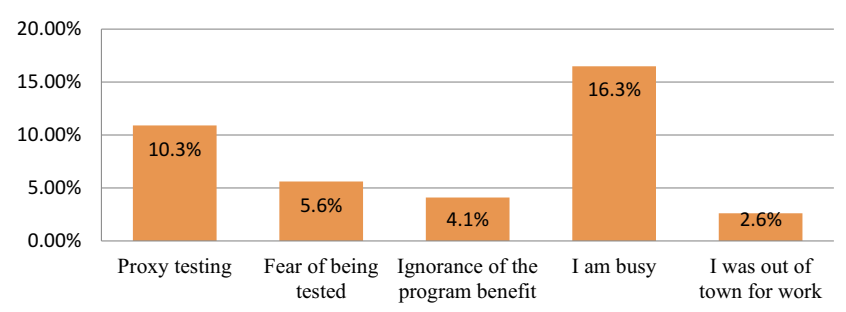

Figure 2 Partners of pregnant woman reason for not being tested in Addis Ababa, Ethiopia, 2019.

attended the antenatal clinic accepted HIV counseling and testing for HIV. ${ }^{15}$ The less partner HIV test in this study was attributed to being busy, which is the same as the study found in Goba. ${ }^{16}$ Another reason attributed to men not being tested was proxy testing the finding is congruent with that of the study done by Goba in Ethiopia. ${ }^{16}$ But compared to the study that was made in Addis Ababa it is higher which shows 44\% reported having been tested during the partner's pregnancy. ${ }^{25}$ And this might be due to an increment of knowledge and awareness on HIV and PMTCT.

There are many factors associated with partner HIV test status, from this study Knowledge on the route of HIV transmission from mother to child ways had a positively associated with a partner HIV test. As the study in Gondar revealed, the likelihood of male involvement in HCT was found to be higher among those who knew the time and route of HIV from mother to child. ${ }^{17}$ This evidence is also supported by the study conducted by Goba, those partners who knew modes of HIV transmission from mother to the child were more to receive HIV Counseling and testing compared to those who do not know. ${ }^{16}$ This might be due to an increased level of knowledge and awareness about HCT expected to have a positive influence on men's involvement in HCT.

Couples who received HIV counseling and testing before had a positive association with partner HIV test. This is similar to a study from Midlands Province, Zimbabwe showed, those who previously tested for HIV with their wives as a couple is significantly associated with partner HIV testing and involvement in PMTCT. ${ }^{12}$ 
Table 3 Bivariable and Multivariable Analysis Result for Variables Associated with Partner HIV Test in Addis Ababa, Ethiopia, 2019

\begin{tabular}{|c|c|c|c|c|c|}
\hline \multirow[t]{2}{*}{ Variables } & \multicolumn{2}{|c|}{ Tested } & \multirow[t]{2}{*}{ COR(95\% Cl) } & \multirow[t]{2}{*}{ AOR(95\% Cl) } & \multirow[t]{2}{*}{ P-value } \\
\hline & Yes & No & & & \\
\hline \multicolumn{6}{|l|}{ Education status } \\
\hline No formal education & 14 & 30 & $\mathrm{I}$ & I & \\
\hline Primary school (I-8) & 62 & 77 & $1.7(0.8-3.5)$ & $0.5(0.17-1.8)$ & 0.358 \\
\hline Secondary school (9-12 & 168 & 112 & $3.2(1.6-6.3)$ & $0.8(0.2-2.584)$ & 0.750 \\
\hline College and above & 264 & 71 & $7.9(4.0-15.8)$ & $1.0(0.3-3.6)$ & 0.885 \\
\hline \multicolumn{6}{|l|}{ Occupation } \\
\hline Governmental employee & 195 & 52 & $7.3(3.9-13.5)$ & $1.4(0.5-3.6)$ & 0.492 \\
\hline Private & 242 & 167 & $2.8(1.5-5.0)$ & $1.2(0.4-2.9)$ & 0.688 \\
\hline NGO & 51 & 32 & $3.1(1.5-6.2)$ & I.0(0.3-2.95) & 0.941 \\
\hline Daily labor & 20 & 39 & 1 & 1 & \\
\hline \multicolumn{6}{|c|}{ Knowledge on modes of HIV transmission } \\
\hline Yes & 457 & 225 & 1 & 1 & \\
\hline No & 51 & 65 & $2.5(1.7-3.8)$ & $1.5(0.97-2.4)$ & 0.067 \\
\hline \multicolumn{6}{|c|}{ Knowledge on route of HIV transmission from mother to child } \\
\hline Yes & 380 & 130 & 1 & 1 & \\
\hline No & 128 & 160 & $3.6(2.6-4.9)$ & $1.9(1.3-2.7)$ & $0.000^{*}$ \\
\hline \multicolumn{6}{|c|}{ Knowledge on prevention of HIV from mother-to-child transmission } \\
\hline Yes & 259 & 47 & $0.18) .13-26)$ & $0.26(0.17-0.38)$ & $0.000^{*}$ \\
\hline No & 249 & 243 & I & I & \\
\hline \multicolumn{6}{|c|}{ Knowledge on the presence of HCT during ANC visit } \\
\hline Yes & 472 & 206 & $5.3(3.5-8.1)$ & $1.1(0.6-2.2)$ & 0.642 \\
\hline No & 36 & 84 & 1 & 1 & \\
\hline \multicolumn{6}{|c|}{ Think partner testing is necessary } \\
\hline Yes & 506 & 257 & $32.4(7.7-136.4)$ & $4.8(0.7-30.2)$ & 0.088 \\
\hline No & 2 & 33 & I & I & \\
\hline \multicolumn{6}{|c|}{ Ever received couple HIV counseling testing before } \\
\hline Yes & 440 & 153 & $5.7(4.1-8.1)$ & $3.7(2.3-6.1)$ & $0.000 *$ \\
\hline No & 68 & 137 & I & I & \\
\hline \multicolumn{6}{|c|}{ Discussed about HCT ANC services with your partner } \\
\hline Yes & 404 & 78 & $10.5(7.5-14.7)$ & $6.3(4.0-9.8)$ & $0.000^{*}$ \\
\hline No & 104 & 212 & I & 1 & \\
\hline \multicolumn{6}{|c|}{ Heard about discordant HIV test result } \\
\hline Yes & 439 & 160 & $5.1(3.6-7.2)$ & $2.3(1.4-4.0)$ & $0.00 I^{*}$ \\
\hline No & 69 & 130 & 1 & 1 & \\
\hline
\end{tabular}

Notes: *Statistically significant at $95 \% \mathrm{Cl}, \mathrm{P}<0.05, \mathrm{I}=$ reference.

Abbreviations: $\mathrm{COR}$, crude odds ratio; $\mathrm{AOR}$, adjusted odds ratio; $\mathrm{Cl}$, confidence interval.

A study in Mekele revealed that partners who had been counseled and tested with wife were 5 times higher to go to ANC/PMTCT clinic and get HIV test than their counterparts. ${ }^{21}$ This implies that promoting couple HIV testing and counseling in all ANC and other HCT entry points might enhance male involvement in HIV testing. 
Respondents who ever discussed ANC and HCT with their spouse were significantly associated with partner HIV tests. A study done in Midlands Province, Zimbabwe, mentioned male partners who received feedback from their wives on ANC issues were significantly more likely to be involved in PMTCT than those who did not receive any feedback. ${ }^{12}$ Those partners who reported discussion about HCT with their wives had increased odds of involvement in HCT compared to their counterparts. ${ }^{17}$ This suggests that open discussion between couples regarding HIV result is an important factor in increasing the number of men accompanying their spouses to antenatal clinics and accessing HIV counseling and testing services. Studies reported that poor discussion habit on ANC service utilization and the importance of couple HTC between partners was associated with poor male involvement in PMTCT. ${ }^{11,18,19,23,26}$

For this study awareness of discordant HIV test results among respondents was also one of the factors associated with partner HIV test. As the study in Rwanda and Zambia stated that awareness about sero-discordance was less. Low knowledge of the possibility of couple serodiscordance is a barrier to Couple HIV counseling and test uptake. ${ }^{22}$ For this study results on awareness for serodiscordance might be high due to the information provided on HIV sero-discordance, where to access services, and the importance of HCT to prevent HIV transmission between partners.

\section{Conclusion and Recommendation Conclusion}

HIV testing service utilization among pregnant women in the current study area was low, where national coverage in urban areas was $72 \%$. The partner HIV testing was significantly higher among partners who have a knowledge on ways of prevention of transmission of HIV from mother to child, those who received couple HIV counseling before, those who discussed HCT at ANC services with a partner and heard about discordant HIV test result.

\section{Recommendation}

\section{Addis Ababa Health Bureau Should}

- Increase the community awareness on male partner accompanying and testing service utilization during ANC follow-up to strengthen PMTCT.

- Advocate the greater importance of male partner testing during ANC/PMTCT.

\section{Stakeholders and NGO Partners Should}

- Provide training on ANC/PMTCT.

\section{Health Care Providers Should}

- Encourage male partner to accompany their pregnant spouse during ANC visit to get comprehensive ANC care,

- Provide health education regarding ANC/PMTCT places where men gather,

- Discuss about HCT at ANC with partner, disclosure of HIV test status and encourage the women to bring their partner.

\section{Abbreviations}

AIDS, acquired immune deficiency syndrome; ANC, antenatal care; ART, antiretroviral therapy; CHTC, couple HIV testing and counseling; C/S, cesarean section; FGD, focused group discussion; HIV, human immunodeficiency virus; HCT, HIV counseling and testing; HEWs, health extension workers; $\mathrm{MCH}$, maternal child health; PMTCT, Prevention of Mother to child transmission; SRH, sexual reproductive health; STI, sexual transmitted infections; UNAIDS, United Nation Programme on HIV and AIDS; UK, United Kingdom; VCT, voluntary counselingand testing; VLS, viral load suppression; WHO, World Health Organization.

\section{Acknowledgment}

We would like to express gratitude to individuals who contributed their effort for their consistent and constructive comments.

\section{Disclosure}

The authors report no conflicts of interest for this work.

\section{References}

1. MAyo Mc. HIV/AIDS. Available from: https://www.mayoclinic.org/ diseases-conditions/hiv-aids/symptoms-causes/syc-20373524. Accessed January 12, 2021. 2017.

2. AVERT. Global information and education on HIV and AIDS, what are HIV/AIDS. Available from: https://www.avert.org/about-hiv-aids /what-hiv-aids. Accessed January 12, 2021.

3. UNAIDS. 90-90-90: an ambitious treatment target to help end the AIDS epidemic'. 2014.

4. AVERT. Global information and education on HIV and AIDS, PMTCT. Available from: https://www.avert.org/professionals/hiv-programming /prevention/prevention-mother-child. Accessed January 12, 2021.

5. WHO. Guidance on Couples HIV Testing and Counseling Including Antiretroviral Therapy for Treatment and Prevention in Serodiscordant Couples: Recommendations for a Public Health Approach. 2012. 
6. Masters SH, Agot K, Obonyo B, Mavedzenge SN, Maman S, Thirumurthy H. Promoting partner testing and couples testing through secondary distribution of HIV self-tests: a randomized clinical trial. PLoS Med. 2016;13(11):e1002166. doi:10.1371/journal. pmed.1002166

7. UNAIDS. UNAIDS 'AIDS info. 2017. Available from: https://www. aidsdatahub.org/unaids-data-2017-unaids-2017-0. Accessed January 12, 2021.

8. WHO. Guidelines on HIV Self-Testing and Partner Notification: Supplement to Consolidated Guidelines on HIV Testing Services. 2016.

9. Sidibé M, Loures L, Samb B. The UNAIDS 90-90-90 target: a clear choice for ending AIDS and for sustainable health and development. $J$ Int AIDS Soc. 2016;19(1):21133. doi:10.7448/IAS.19.1.21133

10. UNAIDS. Blindspot: addressing a blind spot in the response to HIV Reaching out to men and boys'. 2017. Available from: https://data. unicef.org/wp-content/uploads/2018/06/blind spot en.pdf. Accessed January 12, 2021.

11. Morfaw F, Mbuagbaw L, Thabane L, et al. Male involvement in prevention programs of mother to child transmission of HIV a systematic review to identify barriers and facilitators. Syst Rev. 2013;2(1):5. doi:10.1186/2046-4053-2-5

12. Makoni A, Chemhuru M, Chimbetete C, Gombe N, Bangura D, Tshimanga M. Factors associated with male involvement in the prevention of mother to child transmission of HIV, Midlands Province, Zimbabwe, 2015-a case-control study. BMC Public Health. 2016;16 (1):331. doi:10.1186/s12889-016-2939-7

13. Aarnio P, Olsson P, Chimbiri A, Kulmala T. Male involvement in antenatal HIV counseling and testing: exploring men's perceptions in rural Malawi. AIDS Care. 2009;21(12):1537-1546. doi:10.1080/ 09540120902903719

14. Ditekemena J, Koole O, Engmann C, et al. Determinants of male involvement in maternal and child health services in sub-Saharan Africa: a review. Reprod Health. 2012;9(1):32. doi:10.1186/17424755-9-32

15. Byamugisha R, Åstrøm AN, Ndeezi G, Karamagi CA, Tylleskär T, Tumwine JK. Male partner antenatal attendance and HIV testing in eastern Uganda: a randomized facility-based intervention trial. $J$ Int AIDS Soc. 2011;14(1):43. doi:10.1186/1758-2652-14-43
16. Alemayehu M, Haidar J. Male involvement in prevention of mother-to-child transmission of HIV in the context of partner testing in Goba town, Ethiopia: a facility-based cross-sectional study. $S$ Afr Med J. 2017;107(10):10. doi:10.7196/SAMJ.2017.v107i10.11371

17. Zenebe A, Gebeyehu A, Derseh L, Ahmed KY. Male partner's involvement in HIV counseling and testing and associated factors among partners of pregnant women in Gondar town, Northwest Ethiopia. J Pregnancy. 2016;2016:1-6. doi:10.1155/2016/3073908

18. Ditekemena J, Matendo R, Koole O, et al. Male partner voluntary counseling and testing associated with the antenatal services in Kinshasa, Democratic Republic of Congo: a randomized controlled trial. Int $J$ STD AIDS. 2011;22(3):165-170. doi:10.1258/ ijsa.2010.010379

19. Byamugisha R, Tumwine JK, Semiyaga N, Tylleskär T. Determinants of male involvement in the prevention of mother-to-child transmission of HIV program in Eastern Uganda: a cross-sectional survey. Reprod Health. 2010;7(1):12. doi:10.1186/1742-4755-7-12

20. Farquhar C, Kiarie JN, Richardson BA, et al. Antenatal couple counseling increases the uptake of interventions to prevent HIV-1 transmission. J Acquir Immune Defic Syndr. 2004;37(5):1620. doi:10.1097/00126334-200412150-00016

21. Haile F, Brhan Y. Male partner involvements in PMTCT: a cross-sectional study, Mekelle, Northern Ethiopia. BMC Pregnancy Childbirth. 2014;14(1):65. doi:10.1186/1471-2393-14-65

22. Kelley AL, Karita E, Sullivan PS, et al. Knowledge and perceptions of couples' voluntary counseling and testing in urban Rwanda and Zambia: a cross-sectional household survey. PLoS One. 2011;6(5):5. doi:10.1371/journal.pone.0019573

23. CSA. Central Statistics Agency. 2014.

24. Addis Ababa City Adminstration Health Buraeu. Annual Activity Report. Addis Ababa, Ethiopia: Addis Ababa City Adminstration Health Buraeu; 2015.

25. Getu DK Factors related to male participation in prevention of mother-to-child transmission of human immunodeficiency virus in three public hospitals in Addis Ababa, Ethiopia 2011.

26. Haileamlak A. Will Ethiopia achieve the global target of 90-90-90? Ethiop J Health Sci. 2019;29(3):298. doi:10.4314/ejhs.v29i3.1
HIV/AIDS - Research and Palliative Care

\section{Publish your work in this journal}

HIV/AIDS - Research and Palliative Care is an international, peerreviewed open-access journal focusing on advances in research in HIV, its clinical progression and management options including antiviral treatment, palliative care and public healthcare policies to control viral spread. The manuscript management system is completely online and includes a very quick and fair peer-review system, which is all easy to use. Visit http://www.dovepress.com/testimonials.php to read real quotes from published authors. 